\title{
ERRATUM
}

\author{
Arkadiusz Kuroś • Przemyław Kościk • Jayanta K. Saha
}

\section{Erratum to: Doubly Excited Resonance States of Helium Atom: Complex entropies}

Published online: 16 February 2017

(C) Springer-Verlag Wien 2017

\section{Erratum to: Few-Body Syst (2016) 57:1147-1153 \\ DOI 10.1007/s00601-016-1151-8}

Under the framework of the complex-scaling method, the expectation value of a given complex scaled operator $\hat{A}$ has a form $\ll \hat{A} \gg=\operatorname{Re} \ll \varphi_{L}|\hat{A}| \varphi_{R} \gg[1]$. Following to [1], the imaginary part of $\ll \varphi_{L}|\hat{A}| \varphi_{R} \gg$ can be interpreted as the uncertainty in the determination of the mean value only in the case when $\hat{A}$ commutes with the corresponding Hamiltonian, $(\Delta A)^{2}=-\left(\operatorname{Im} \ll \varphi_{L}|\hat{A}| \varphi_{R} \gg\right)^{2}$. We have incorrectly written in the article that the above occurs for every operator $\hat{A}$. In view of the above, in the original article [2], the discussion regarding the meaning of the imaginary parts of the complex entropies is incorrect. This misunderstanding does not affect any of the main results introduced in the article. However, to understand the physical meaning of the complex entropy, more constructive analysis is still needed.

\section{References}

1. T. Berggren, Expectation value of an operator in a resonant state. Phys. Lett. B 373, 1 (1996)

2. A. Kuroś, P. Kościk, J.K. Saha, Doubly excited resonance states of helium atom: complex entropies. Few Body Syst. 57, 1147 (2016)

The online version of the original article can be found under doi:10.1007/s00601-016-1151-8.

A. Kuroś (囚). P. Kościk

Institute of Physics, Jan Kochanowski University, ul. Świętokrzyska 15, 25-406 Kielce, Poland

E-mail: akuros@ujk.edu.pl

J. K. Saha

Aliah University, II-A/27, Newtown, Kolkata 700156, India 